\title{
A LEI DA PALMADA E SEUS IMPACTOS NA LDB: INSERÇÃO DA TRANSVERSALIDADE ATRAVÉS DA EDUCAÇÃO EM DIREITOS HUMANOS E DA PREVENÇÃO DE VIOLÊNCIAS CONTRA A CRIANÇA E O ADOLESCENTE
}

\section{LA LEY DE AZOTES Y SU IMPACTO EN LDB: INSERCIÓN TRANSVERSAL DE LA EDUCACIÓN EN DERECHOS HUMANOS Y DE LA PREVENCIÓN DE LA VIOLENCIA CONTRA LOS NIÑOS Y ADOLESCENTES}

\author{
${ }^{1}$ Maria Aparecida Alkimin
}

\section{RESUMO}

O presente estudo traz à tona o sentido holístico do processo ensino-aprendizado e a realidade do cotidiano escolar, no sentido de demonstrar que o processo educacional e a função da escola vão além da transmissão, absorção, recepção e reprodução por parte dos educandos dos conhecimentos que compõem os currículos de formação básica. Demonstrarse-á que, hodiernamente, a transversalidade, através de ensinamentos e vivências das diversas áreas do conhecimento humano, em especial dos direitos humanos, são elementares para a formação plena e integral da criança e do adolescente, que necessitam de educação em valores humanos para o despertar da consciência cidadã e do papel protagonista na sociedade em que vivem. Nesse sentido, será demonstrado que a Lei da Palmada (Lei n. 13010/2014) prevê a proteção contra todas as formas de violências contra a criança e o adolescente, mas que também refletiu diretamente na LDB (Lei n. 9394/1996), ao estabelecer a inserção nos currículos escolares de conteúdos relacionados a valores humanos e de prevenção de todas as formas de violências contra crianças e adolescentes.

Palavras-chave: Criança e adolescente, Educação, Transversalidade, Violência, Direitos humanos

\footnotetext{
${ }^{1}$ Doutora em Direito pela Pontifícia Universidade Católica - PUC, São Paulo - SP (Brasil). Professora do Centro Universitário Salesiano São Paulo, Lorena. (Brasil). E-mail: maalkimin@terra.com.br
} 


\section{RESUMEN}

Este estudio pone de manifiesto el sentido holístico del proceso de enseñanza-aprendizaje y la realidad de la vida de la escuela todos los días, para demostrar que el proceso educativo y la función de la escuela van más allá de la transmisión, la absorción, la recepción y la reproducción por los alumnos de los conocimientos que conforman el plan de estudios de la educación básica. Demuestra que, en nuestros tiempos, la transversal a través de enseñanzas y experiencias de las diversas áreas del conocimiento humano, especialmente los derechos humanos, son fundamentales para la formación plena e integral de los niños y adolescentes, que necesitan educación en valores humano para el despertar de la conciencia social y el papel protagonista en la sociedad en que viven. En este sentido, se demostrará que la Ley de Nalgadas (Ley n. 13010/2014) ofrece protección contra todas las formas de violencia contra los niños y adolescentes, pero también refleja directamente en la LDB (Ley n. 9394/1996) para establecer la inclusión en los programas escolares de contenidos relacionados con los valores humanos y prevenir toda forma de violencia contra los niños, niñas y adolescentes.

Palabras-claves: Niños y adolescentes, Educación, Transversal, Violencia, Derechos humanos 


\section{INTRODUÇÃO}

É cediço que a educação é um processo natural atrelado ao desenvolvimento da pessoa em todas a suas dimensões: social, familiar, cultural, profissional etc, cujo processo a capacita para a convivência em grupo, através da aquisição de conhecimentos e vivências, absorvidas mediante transferências de experiências e conhecimentos alheios, sendo certo que o aprendizado se inicia desde o primeiro momento de inserção no meio familiar e social, ou seja, através do nascimento.

Nesse sentido, busca-se demonstrar no presente trabalho que a educação corresponde a um direito natural da pessoa humana, cujo direito humano à educação uma vez positivado e incorporado ao ordenamento jurídico internacional e nacional sob a forma de direito social e fundamental, impõe à família, à sociedade e ao Estado o dever prestacional, ou seja, de destinar à criança e ao adolescente, em especial, educação com espírito de paz, amor, dignidade, tolerância e solidariedade, ou seja, em valores humanos, como forma, inclusive, de concretização do sistema de proteção especial e integral consagrado pela Convenção sobre os Direitos da Criança e pela CF/88 (art. 227).

A presente pesquisa, cujo método envolve análise e invocação do sistema legislativodocumental internacional e legislativo interno de proteção e de garantias aos direitos da criança e do adolescente, em especial, o direito à educação, analisa e contextualiza as normas internacionais e nacionais que vedam todas as formas de violência, tratamento cruel e degradante que afetem o desenvolvimento sadio e equilibrado das crianças e adolescentes.

Esse trabalho de pesquisa também envolve uma análise da LDB acerca da inserção da transversalidade nos currículos escolares, como mecanismo necessário para formação plena da criança e do adolescente, para uma formação integral e que os tornem cidadãos conscientes e transformadores da sociedade em que vivem.

Nesse sentido, à luz do sistema legislativo interno protetivo, far-se-á uma análise da Lei da Palmada ( Lei n. 13.010 de 26/6/2014) que, atrelada ao sistema de proteção integral estatuído pelo art. 227 da CF, tem como objetivo acrescentar à Lei $n^{\circ}$ 8.069, de 13 de julho de 1990 (Estatuto da Criança e do Adolescente), os artigos 18A e 18B, enfatizando o direito da criança e do adolescente de serem educados e cuidados sem o uso de castigos físicos ou de tratamento cruel ou degradante. 
No mesmo viés, demonstrar-se-á que a referida Lei da Palmada refletiu diretamente na LDB (Lei de Diretrizes e Bases da Educação Nacional, Lei no 9.394, de 20/12/1996) e acrescentou ao artigo 26 dessa lei educacional o parágrafo $9^{\circ}$. que prevê a inclusão com temas transversais nos currículos escolares conteúdos relativos a direitos humanos e à prevenção de todas as formas de violência contra a criança e o adolescente.

Assim sendo, será demonstrado que o processo ensino-aprendizado é holístico, ou seja, visa a formação integral e plena da criança e adolescente, como pessoas em peculiar condição de desenvolvimento, e que, para assunção do papel protagonista na sociedade em que vivem, necessitam de uma educação centrada, não apenas em recepção e transmissão de aprendizados e conhecimentos, mas, também, de conteúdos transversais ligados aos direitos humanos que despertarão a consciência humana e cidadã e que, inclui, por obviedade, a prevenção de todas as formas de violências e atentados contra essa parcela vulnerável da população.

\section{O DIREITO À EDUCAÇÃO E A TRANSVERSALIDADE NO PROCESSO ENSINO-APRENDIZAGEM À LUZ DA LDB}

A educação compõe o processo de evolução, adaptação, iteração e socialização da pessoa no meio em que vive, cujo processo envolve apreensão de conhecimentos, afirmação de valores humanos, éticos e morais para a formação integral da pessoa humana.

A educação tem a finalidade de capacitar para o convívio e proporcionar a apreensão de modos de agir, pensar e sentir que transformam o individuo, nas diversas fases da vida, em pessoas formadas, socializadas e que gozam do pleno exercício dos direitos fundamentais, sociais e políticos, capazes de proporcionar uma vida digna e feliz.

O processo educativo, na verdade, tem sua origem desde o nascimento com vida, quando o ser humano, passando a integrar o meio familiar e social, recebe os primeiros cuidados e aprendizados, logo, trata-se de um processo natural ligado ao desenvolvimento humano, onde gerações adultas, dotadas de conhecimentos nas mais variadas áreas do saber, influenciam o processo de formação e socialização da pessoa, desde o seu nascimento.

Nesse sentido, oportunas as palavras de FORRACHI:

A educação é a ação exercida pelas gerações adultas sobre as gerações que não se encontram ainda preparadas para a vida social; tem por objeto suscitar e desenvolver, na criança, certo número de estados físicos, intelectuais e morais, 
reclamados pela sociedade política no seu conjunto e pelo meio especial a que a criança, particularmente, se destine. (1971, p. 42)

A educação corrobora para o processo de formação da criança e do adolescente em todas as suas dimensões: intelectual, sentimental, moral, humana, profissional e social, permitindo-lhe progressiva liberdade, autonomia e autodeterminação para condução de sua vida.

Pode-se afirmar que a educação conduz à autonomia e autodeterminação e, consequentemente, permite o gozo e fruição dos direitos no âmbito da convivência em sociedade. Logo, à luz da filosofia Kantiana, no uso da razão e autodeterminação, o homem só se reconhece como fim em si mesmo, quando transpassa pelo processo educativo que o levará à liberdade.

Educação não significa apenas transmissão e apreensão de conhecimentos, saberes e experiências, educação deve ser voltada para a formação integral do cidadão para o pleno exercício dos direitos civis e políticos e com base na ética humanitária para o desenvolvimento do espírito de cooperação e solidariedade com vistas à responsabilidade social.

Sob o aspecto sociológico, a educação constitui fator elementar para o pleno desenvolvimento da criança e do adolescente, preparando-a para uma vida independente na sociedade e que envolve o exercício da cidadania e a qualificação para o trabalho, devendose ressaltar que a Convenção sobre Direitos da Criança em seu Preâmbulo proclama que a criança deve ser educada com espírito de paz, dignidade, tolerância, liberdade, igualdade e solidariedade.

A Constituição Federal de 1988, ao atribuir ao direito à educação e seu acesso universal, o caráter de direito social e fundamental, visou não somente a concretização da proteção integral à criança e ao adolescente, como também concretizar os objetivos do Estado Democrático de Direito e do Bem-Estar Social, disciplinando os direitos sociais que correspondem à extensão da dignidade da pessoa humana (art. $1^{\circ}$.,III,da CF).

Tratando-se de direito social e fundamental impõe ao Estado o dever de fazer, ou seja, um dever prestacional, logo, incumbe ao Estado a prestação educacional com o estabelecimento de políticas públicas que permita o acesso universal e igualitário de todos à educação, podendo os pais ou outro responsável legal exigir do Poder Público o acesso ao ensino obrigatório.

O Estado tem o dever jurídico de oferecer, estimular, fomentar o acesso à educação, conforme já se ressaltou alhures, sendo certo que o dever de proteção integral à criança e ao 
adolescente envolve a participação da família, conforme estabelecido pelo art. 227 da CF, competindo à família, ou seja, aos pais o dever de matricular seus filhos no ensino obrigatório, além de acompanhar a frequência e o aproveitamento escolar (arts. 55 e 129, V, do ECA).

Como corolário do direito à educação, há também o direito ao convívio num meio ambiente escolar sadio e equilibrado e, consequentemente, dever da iniciativa privada e do Estado, além de impor à família o dever de vigilância, zelo e cuidado no que tange à sadia qualidade e equilíbrio nas relações e convívio escolar. Nesse sentido, é oportuno invocar o disposto no art. 70 do ECA: "é dever de todos prevenir a ocorrência de ameaça ou violação dos direitos da criança e do adolescente."

Sem dúvida, a escola e a família zelando pela qualidade de vida das crianças e adolescentes nas relações escolares estarão zelando, protegendo e prevenindo danos à saúde física e psíquica das crianças e adolescentes oriundos das violências, agressividades ou incivilidades típicas do meio ambiente escolar.

Somente se atingirá os objetivos de um Estado Democrático de Direito por intermédio de uma educação com acesso universal e igualitário; sendo certo que a educação e o acesso à educação de modo universal e igualitário é uma condição elementar para sobrevivência do Estado Democrático de Direito.

Não é de se olvidar que o direito à educação e o efetivo exercício do direito à educação integram o sistema de garantias e de proteção integral à criança e ao adolescente, conforme previsto no art. 227 da $\mathrm{CF} / 88$, que trata do dever proteção integral à cargo da família, da sociedade e do Estado.

O ECA em seu artigo $4^{\circ}$., caput, assegura à criança e ao adolescente, com absoluta prioridade, a efetivação, por parte da família, da sociedade e do Estado, dos direito fundamentais referentes à vida, à saúde, à alimentação, à educação, ao esporte, ao lazer, à profissionalização, à cultura, à dignidade, ao respeito, à liberdade e a convivência familiar e comunitária

A Educação é um direito social e fundamental da criança e do adolescente de caráter geral, posto que disciplinado pela $\mathrm{CF} / 88$ e de caráter especial diante da sua regulamentação pelo sistema de proteção infraconstitucional que é o ECA (Estatuto da Criança e do Adolescente, Lei n. 8090/90).

Trata-se, o direito à educação, de garantia fundamental e de um direito subjetivo público (art. 208,CF), inerente ao ser humano, portanto, indissociável de sua dignidade 
humana, onde o homem pela simples condição humana é titular de direitos subjetivos que devem ser "reconhecidos e respeitados por seus semelhantes e pelo Estado". (TEIXEIRA, 1996, p. 99 apud PEREIRA, 2008, p. 522)

$\mathrm{O}$ art. $4^{\circ}$. da LDB (Lei de Diretrizes e Bases da Educação Nacional, Lei n. 9394/1996), na esteia da CF e do art. 53 do ECA dispõe que o Estado tem o dever de conceder educação escolar pública, mediante a garantia de: educação básica obrigatória e gratuita dos 4 aos 17 anos de idade, cuja educação obrigatória abrange: pré-escola; ensino fundamental; ensino médio. Portanto, a educação básica compreende a educação infantil, o ensino fundamental e o ensino médio, constitui, de acordo com a ordem jurídica constitucional, um direito social básico para a vida das pessoas, sendo que a educação básica e fundamental representa o alicerce para construção da cidadania e que permite o desenvolvimento pleno através do conhecimento, contribuindo para a inserção do individuo na sociedade.

Pode-se, afirmar, nesse sentido, que o direito à educação tem sua base no direitodever estatal que tratou da positivação dos direitos e garantias fundamentais do cidadão no intuito de garantir uma vida digna, embora haja responsabilidade solidária do Estado, da família e da sociedade (arts.205 e 227 da CF) no que tange ao atendimento e ao acesso ao ensino fundamental que deve ser destinado à criança e ao adolescente.

O processo educativo, em todos os seus níveis, deve visar a formação integral, ou seja, aquela que abrange a formação pessoal e profissional, preparando o homem para o convívio harmônico na sociedade com base em valores humanos que convergem para o respeito e consideração ao próximo, manifestação do espírito solidário e humano, como também a formação técnica-profissional para a busca de condições dignas de trabalho e de sobrevivência.

Para esse desiderato, importante frisar o papel da escola, elemento preponderante para a formação integral e desenvolvimento pleno das crianças e jovens, sendo a escola, ao lado da família, o espaço de integração social e de socialização para a formação cidadã e efetivo exercício da cidadania.

De acordo com o artigo $2^{\circ}$. da LDB (Lei de Diretrizes e Bases da Educação Nacional), os princípios e fins da educação nacional ditam que "a educação, dever da família e do Estado, inspirada nos princípios de liberdade e nos ideais de solidariedade humana, tem por finalidade o pleno desenvolvimento do educando, seu preparo para o exercício da cidadania e sua qualificação para o trabalho." 
Contudo, para a concretização da formação integral da criança, do adolescente e do jovem, importante papel exerce a transversalidade dos conteúdos educacionais que compõem os currículos escolares.

Com efeito, se a educação está voltada para a formação da pessoa humana em seus múltiplos sentidos e aspectos, possibilitando a vivência e convivência humana na paz, na compreensão, na tolerância, no cuidado e respeito ao outro, na solidariedade e fraternidade, de suma importância a transversalidade dos conteúdos escolares no processo educacional e de formação da criança, do adolescente e do jovem, visando uma formação pluralista e holística, numa sociedade repleta de adversidades.

Nesse sentido, a Lei de Diretrizes e Bases da Educação Nacional (LDB) que disciplina a estrutura e o funcionamento do sistema escolar brasileiro, busca além da formação básica, profissional do cidadão, a formação em direitos humanos, os quais abrangem a cidadania, pleno exercício dos direitos civis e políticos e mecanismos de prevenção de todas as formas de violência contra a criança e o adolescente; visando a unidade em meio à diversidade que caracteriza o país.

De acordo com a LDB, com todas as alterações sofridas desde a sua primeira edição, inclusive a mais recente provocada pela Lei da Palmada (Lei n. 13010/2014), a transversalidade busca atribuir uma visão holística ao processo ensino-aprendizagem, para a formação integral da criança, do adolescente e do jovem, além de proporcionar a formação de um cidadão autônomo e participativo.

A tendência hodierna, portanto, é a integração, inclusive no nível superior, de conteúdos interdisciplinares e transversais visando a formação integral baseada na socialização, cidadania com conhecimento e apreensão de conceitos e valores humanos como dignidade humana, tolerância, ética, respeito ao próximo, enfim, valores que compõem a formação da pessoa humana, além de despertar o conhecimento, interesse e valoração aos símbolos nacionais, culturas locais e nacionais e a preservação ambiental para gerações presentes e futuras.

Nessa linha pedagógica, o ensino básico, dentre outros objetivos, tem como objetivo primordial a formação da criança, adolescente e jovem para compreender, aprender e apreender o exercício pleno da cidadania com participação social e política, assim como exercício de direitos e deveres políticos, civis e sociais, adotando, no dia-a-dia, atitudes de solidariedade, cooperação e repúdio às injustiças, respeitando o outro e exigindo para si o mesmo respeito. 
Em matéria de transversalidade, a LDB já vem passando por alterações gradativas, inclusive, o artigo 32 da $\operatorname{LDB}(9.394$, de 20 de dezembro de 1996) foi regulamentado por Lei Federal (Lei n. 11.525/2007) para inclusão obrigatória de temas transversais, tais como conteúdo que trate dos direitos das crianças e dos adolescentes, tendo como diretriz a Lei $\mathrm{n}^{\circ}$

8.069, de 13 de julho de 1990, que institui o Estatuto da Criança e do Adolescente, observada a produção e distribuição de material didático adequado. (LDB, Lei n. parágrafo $5^{\circ}$.), além de conteúdo transversal referente ao estudo sobre os símbolos nacionais. $\left(\S 6^{\circ}\right)$.

Recentemente, a Lei n. 13.010 de 26 de junho de 2014, a qual passou a ser denominada de "Lei da Palmada", que disciplina o direito da criança e do adolescente de serem criados e educados sem o uso de castigos físicos ou de tratamento cruel ou degradante, reflete diretamente da LDB, pois conforme se verifica pela análise do artigo $3^{\circ}$., da Lei da Palmada, foi acrescentado ao art. 26 da LDB o parágrafo $9^{\circ}$. que impõe a inserção nos currículos escolares de conteúdos relacionados à educação em Direitos Humanos e a medidas de prevenção contra todas as formas de violências contra a criança e o adolescente. (Lei n. 13.010/2014, art. $3^{\circ}$.)

Dessa forma, o artigo 26 da LDB que organiza, regulamenta e disciplina o processo ensino-aprendizagem estabelece a obrigatoriedade de formação dos currículos escolares com a inclusão de temas transversais ligados a conteúdos relativos aos direitos humanos e à prevenção de todas as formas de violência contra a criança e o adolescente, conforme será abordado com mais profundidade adiante.

\section{EDUCAÇÃO EM DIREITOS HUMANOS E A ESCOLA COMO ESPAÇO PARA FORMAÇÃO INTEGRAL}

O processo educativo da criança, adolescente e do jovem visando a formação plena e integral, conscientes da sua condição de sujeitos de direitos e protagonistas no exercício da cidadania e do gozo dos direitos fundamentais, sociais e políticos, com pleno desenvolvimento da personalidade e pleno amadurecimento humano, exige uma educação centrada nos Direitos Humanos, consagrados pela Organização das Nações Unidas (ONU) em1948, além de outros documentos internacionais que também regulam direitos humanos, ligados ao exercício dos direitos sociais, civis e políticos. 
Direitos Humanos correspondem a um conjunto de faculdades e instituições que, em cada momento histórico, concretiza as exigências de dignidade, liberdade e igualdade humanas, as quais devem ser reconhecidos positivamente pelos ordenamentos jurídicos nos âmbitos nacional e internacional. (ALMEIDA, 2009, p.17). São, na verdade, direitos soberanos, inerentes à pessoa humana, posto que lastreados na natureza humana, logo, são inalienáveis e inseparáveis da pessoa humana. (TELLES JUNIOR, 2008, p. 341)

A educação em Direitos Humanos consta expressamente no preâmbulo da Declaração Universal dos Direitos Humanos de 1948, os seguintes termos:

\begin{abstract}
A presente Declaração Universal dos Direitos do Homem como o ideal comum a ser atingido por todos os povos e todas as nações, com o objetivo de que cada indivíduo e cada órgão da sociedade, tendo sempre em mente essa Declaração, se esforcem, através do ensino e da educação, por promover o respeito a esses direitos e liberdades (n.g.), e pela adoção de medidas progressivas de caráter nacional e internacional, por assegurar o seu reconhecimento e a sua observância universal e efetiva, tanto entre os povos dos próprios Estados-Membros quanto entre os povos dos territórios sob sua jurisdição.
\end{abstract}

Depreende-se que a educação em direitos humanos compreende um processo sistemático e multidimensional que orienta a formação do sujeito de direitos, articulando as seguintes dimensões:

a) apreensão de conhecimentos historicamente construídos sobre direitos humanos e a sua relação com os contextos internacional, nacional e local;

b) afirmação de valores, atitudes e práticas sociais que expressem a cultura dos direitos humanos em todos os espaços da sociedade;

c) formação de uma consciência cidadã capaz de se fazer presente em níveis cognitivo, social, ético e político;

d) desenvolvimento de processos metodológicos participativos e de construção coletiva, utilizando linguagens e materiais didáticos contextualizados;

e) fortalecimento de práticas individuais e sociais que gerem ações e instrumentos em favor da promoção, da proteção e da defesa dos direitos humanos, bem como da reparação de violações.

Para efetivação desses preceitos, importante se faz a revisão da prática pedagógica e inserção no processo ensino-aprendizagem dos ensinamentos e práticas voltadas para a educação em Direitos Humanos, tendo como base a Declaração Universal dos Direitos Humanos de 1948, cuja pedagogia centrada em valores humanos integra as diretrizes do Plano 
Nacional de Educação em Direitos Humanos, que tem por objetivos orientar e definir métodos e mecanismos para a elaboração de Políticas e Planos de Ação voltados à efetivação da Educação em Direitos Humanos.

O Plano Nacional de Educação em Direitos Humanos (PNEDH) foi lançado em 2003 sendo fruto de movimento internacional e discussão no âmbito interno envolvendo vários segmentos da sociedade, visando a defesa e efetivação dos direitos humanos, do fortalecimento da democracia, cujos objetivos estão referendados pela Declaração Universal dos Direitos Humanos de 1948. (SILVA, 2010, p. 41)

Os valores educacionais, dentre eles, a tolerância, integram o preâmbulo da Convenção sobre Direitos da Criança, que assim dispõe: "Considerando que a criança deve estar plenamente preparada para uma vida independente na sociedade e deve ser educada de acordo com os ideais proclamados na Carta das Nações Unidas, especialmente com espírito de paz, dignidade, tolerância, liberdade, igualdade e solidariedade.”(CDC, Preâmbulo)

Bobbio salienta que a tolerância tem como razão moral o respeito à pessoa alheia, e ligando o vocábulo à discriminação encara o problema da tolerância sob duas vertentes: a) tolerância de crenças e opiniões diversas, implicando um discurso sobre verdades contrapostas; b) tolerância para a diversidade física ou social, de cuja problemática surge o preconceito e a discriminação.(BOBBIO, 2004, p. 207) A tolerância "não é desejada porque socialmente útil ou politicamente eficaz, mas sim por ser um dever ético.”.(BOBBIO, 2004, p. 207)

Para Candau, é preciso “ formar pessoas capazes de ser sujeitos de suas vidas, conscientes de suas opções, valores e projetos de referência e atores sociais comprometidos com um projeto de sociedade e humanidade.” (2000, p. 13).Nesse aspecto, Candau também reforça que :

\footnotetext{
A escola assim concebida é um espaço de busca, construção, diálogo e confronto, prazer, desafio, conquista de espaço, descoberta de diferentes possibilidades de expressão e linguagens, aventura, organização cidadã, afirmação da dimensão ética e política de todo processo educativo. (2000, p. 15).
}

Certamente, para concretização da educação em Direitos Humanos, a escola, muito mais que um espaço de construção de saberes, conhecimentos, também deve ser um espaço para construção da cidadania, diálogo sobre valores humanos, enfim, espaço onde se aprende, apreende e pratica valores humanos. A educação em Direitos Humanos é parte integrante do processo de educação, ela tem por objetivo a construção, elaboração, apreensão e formulação de conhecimentos que convergem para a formação da pessoa humana, 
não se limita à apreensão dos conteúdos cognitivos, uma vez que envolve valores, comportamentos e atitudes.

Depois da família, a escola continua sendo um espaço de interação grupal e social, educacional e vocacional, cultural, de apreensão e aprendizado como forma de formação intelectual e de preparação para o futuro, onde se aprende e exerce a cidadania, bem como onde se busca desenvolver o espírito de solidariedade, cooperação e a conduta ética nas relações com o próximo, cujo desenvolvimento tem início na convivência familiar.

A Educação em Direitos Humanos também serve de instrumento para a efetivação da cidadania plena através da construção de conhecimentos, do desenvolvimento de valores, e comportamentos nas relações sociais e interpessoais, visando à não-violência e a paz; além de servir de instrumento para a defesa socioambiental e concretização da justiça social pela defesa e promoção da dignidade da pessoa humana.

Conforme parâmetros estabelecidos pelo Programa Mundial de Educação em Direitos Humanos (PMEDH), a educação em Direitos Humanos abrange não apenas a aprendizagem cognitiva, que leva ao desenvolvimento emocional e social dos envolvidos no processo ensino-aprendizagem, envolve também outras questões e habilidades ligadas à educação formal, à escola como espaço de convívio social e harmônico, aos procedimentos e instrumentos pedagógicos inovadores e construtivos, que despertem a consciência e libertação para o exercício pleno da autonomia, voltado para o respeito e valorização da pessoa humana, respeito à diversidade, buscando a sustentabilidade e a formação da cidadania plena.

Não pairam dúvidas, desta forma, de que a escola é parte integrante do processo de educação, ela tem por objetivo a construção, elaboração, apreensão e formulação de conhecimentos que convergem para a formação da pessoa humana, além de espaço onde se produz e reproduz conhecimentos, também é um espaço social privilegiado no qual se elaboram e definem ações, atitudes pedagógicas, como também deve ser um espaço social onde haja prática e vivência em direitos humanos, despertando a consciência social, ética, humana acerca das concepções de pessoa e mundo.

Portanto, para que o processo de aprendizagem, conhecimento, apreensão e de vivência em Direitos Humanos ocorra, a escola também deve ser um espaço onde se garanta a dignidade, a igualdade de oportunidades, o exercício da participação e de autonomia de seus membros, ou seja, de todos os sujeitos envolvidos na comunidade escolar.

Aida Maria Monteiro Silva assim se manifesta acerca do papel-função da escola: independentemente das suas condições sociais, econômica, culturais e de qualquer 
opção: religiosa, política, orientação sexual. Essa formação é cotidiana, a partir das diferentes formas de interação das pessoas, e isso só é possível em uma ação articulada com outros agentes que participam do trabalho escolar - a família e a comunidade -, uma vez que a vivência de uma educação cidadã deve tomar o cotidiano como referência para analisá-lo., compreendê-lo e modificá-lo. (SILVA, 2010, p. 45)

Para se cumprir os objetivos educacionais e a escola que integra o cotidiano da vida de criança e adolescente cumpra sua real função, elementar que o Estado cumpra seu dever de prestação priorizando política pública educacional voltada para o planejamento escolar envolvendo educação em Direitos Humanos e defesa da personalidade e integridade física e psíquica das crianças e adolescentes, pois somente através da educação em Direitos Humanos que se despertará na criança e no jovem a consciência para uma formação cidadã e humana, onde o homem se torna o centro e fundamento para todas as ações humanas.

Para Aida Maria Monteiro Silva, a educação em Direitos Humanos deve ser compreendida

\begin{abstract}
(...) como um processo sistemático e multidimensional que orienta a formação dos sujeitos de direitos, articulando várias dimensões, como a apreensão de conhecimentos sobre Direitos Humanos; a afirmação de valores, atitudes e práticas que expressam uma cultura de Direitos Humanos; a afirmação de uma consciência cidadã; o desenvolvimento de processos metodológicos participativos; e o fortalecimento de práticas individuais e sociais que gerem ações e instrumentos em favor da promoção e da defesa dos Direitos Humanos.(2010, p. 9)
\end{abstract}

A educação em direitos humanos envolve revisão do planejamento escolar, bem como uma preparação específica dos profissionais da área educacional, visando o envolvimento de todos para a educação em direitos humanos, merecendo, por parte do Estado, tratamento prioritário em política pública educacional e de planejamento escolar, pois é através da educação em direitos humanos que se despertará na criança e no adolescente a consciência para uma formação cidadã e humana, onde o homem se torna o centro e fundamento para todas as ações humanas.

\title{
3 A LEI DA PALMADA ( LEI N. 13.010 DE 26 DE JUNHO DE 2014) E O SISTEMA DE PROTEÇÃO INTEGRAL À CRIANÇA E AO ADOLESCENTE
}

Criança e adolescente, por razões biológicas, psicológicas, morais, culturais, são consideradas pessoas em peculiar condição de desenvolvimento físico, psíquico, moral, intelectual, espiritual, intelectual e social, e, portanto, sujeitos de direitos em condições 
especiais, razão pela qual necessitam de um sistema de proteção especial e integral por parte da família, do Estado e da sociedade.

A Declaração Universal dos Direitos Humanos foi o primeiro documento internacional que reconheceu que a infância tem "direito a cuidados e assistências especiais( art. $2^{\circ}$., DUDH). Reforçando o caráter de ius singulares dos direitos humanos infanto- juvenis, a ONU proclamou em 1959 a Declaração Universal dos Direitos da Criança, através da qual reconhece que a criança, para o seu desenvolvimento integral - físico, psíquico, moral, intelectual, social e espiritual, necessita de proteção e cuidados especiais por parte do Estado, da família e da sociedade.

Em 20 de novembro de 1989, foi proclamada a Convenção sobre os Direitos da Criança (ONU) que implementou em matéria de direitos da criança e do adolescente a doutrina da proteção integral, reconhecendo, definitivamente, a condição de sujeitos de direitos, não obstante a peculiar condição de pessoa em desenvolvimento. A Convenção sobre os Direitos da Criança, na esteia da Declaração Universal dos Direitos do Homem proclamou que a "infância têm direito a cuidados e assistência especiais", e também na esteia da Declaração dos Direitos da Criança, proclamou que "a criança, em virtude de sua falta de maturidade física e mental, necessita de proteção e cuidados especiais, inclusive a devida proteção legal...”, cuja proclamação passou a nortear todo o sistema jurídico-legal de proteção integral e especial à criança e ao adolescente, em grande parte do mundo, considerando os Estados-parte que ratificaram referido documento internacional.

A expressão 'proteção' pressupõe um ser humano protegido e um ou mais seres humanos que o protegem, isto é, basicamente um ser humano que tem necessidade de outro ser humano. Obviamente, este segundo ser humano deve ser mais forte que o primeiro, pois deve ter capacidade para protegê-lo. (PEREIRA, 2008, p. 24).

Visando a concretização da proteção especial e integral, o Brasil adotou o sistema de proteção integral e garantias fundamentais, impondo à família, à sociedade e ao Estado a adoção de ações, medidas etc, no sentido de colocar crianças e adolescentes a salvos de toda e qualquer forma de violência que comprometa o seu pleno e harmonioso desenvolvimento e seu bem-estar, conforme disposto no art. 227 da CF. ${ }^{1}$

\footnotetext{
1 É dever da família, da sociedade e do Estado assegurar à criança e ao adolescente, com absoluta prioridade, o direito à vida, à saúde, à alimentação, à educação, ao lazer, à profissionalização, à cultura, à dignidade, ao respeito, à liberdade e à convivência familiar e comunitária, além de colocá- los a salvo de toda forma de negligência, discriminação, exploração, violência, crueldade e opressão.
} 
Referido artigo constitucional foi regulamentado pelo Estatuto da Criança e do Adolescente (ECA, Lei n. 8069/90), que estabeleceu o sistema de garantias e de proteção aos direitos fundamentais e especiais infanto-juvenis; especiais justamente em razão da condição do caráter de direitos singulares que são destinados a essa parcela da população em estado de vulnerabilidade.

Feitas essas considerações acerca do surgimento do sistema de proteção especial e integral, afirma-se, portanto, que a violência contra a criança ou adolescente, inclusive, sob pretexto educativo e corretivo, não se coaduna com o sistema de proteção e de garantias disciplinado internacionalmente e internamente sob o manto da Proteção Integral e do Melhor Interesse da criança e do adolescente.

O artigo 19 da Convenção sobre os Direitos da Criança dispõe:

Os Estados Partes tomarão todas as medidas legislativas, administrativas, sociais e educacionais apropriadas para proteger a criança contra todas as formas de violência física ou mental, abuso ou tratamento negligente, maus-tratos ou exploração, inclusive abuso sexual, enquanto estiver sob a guarda dos pais, do representante legal ou de qualquer outra pessoa responsável por ela.

Portanto, é notório que no âmbito internacional há um sistema rígido de proteção contra violência infanto-juvenil, seja no âmbito doméstico, na escola, nos espaços de lazer, no local de trabalho etc, sendo vedado qualquer ato que atente à integridade física, moral e psíquica da parcela da população, mesmo sob o pretexto de utilização como forma de castigo educativo ou corretivo por parte de pais, educadores, agentes públicos, enfim, por parte de todo aquele que detiver a guarda ou posse de fato da criança e do adolescente, e a quem incumbe, segundo o referido sistema de proteção, o dever de proteção especial e cuidado especial.

No âmbito interno, o Estatuto da Criança e do Adolescente (ECA, Lei n. 8069/90) estabeleceu no seu artigo 18 que: "É dever de todos velar pela dignidade da criança e do adolescente, pondo-os a salvo de qualquer tratamento desumano, violento, aterrorizante, vexatório ou constrangedor”, buscando, dessa forma, estabelecer um sistema de proteção à criança e ao adolescente contra todo tipo e forma de violência física, psíquica ou sexual.

A Lei 13.010 de 26/6/2014, conhecida como a Lei da Palmada, passou a compor o sistema legislativo infraconstitucional que visa ampliar o sistema de garantias e de proteção aos direitos da criança e do adolescente, disciplinando o direito da criança e do adolescente de serem educados e cuidados sem o uso de castigos físicos ou de tratamento cruel ou degradante, vedando expressamente a utilização dos castigos corporais infligidos à criança e 
ao adolescente, tanto no âmbito doméstico, como na escola, nos abrigos e nas unidades de internação.

Sob o aspecto axiológico, denota-se que a Lei da Palmada está em consonância com a Doutrina da Proteção Integral e com as diretivas dos Comitês das Nações Unidas que impõem aos Estados-partes medidas legislativas no sentido de concretização da proteção integral à criança e ao adolescente.

Na verdade, a Lei da Palmada está em absoluta consonância com o art. 19 da Convenção sobre os Direitos da Criança da ONU, portanto, é uma medida legislativa atrelada ao sistema de proteção à criança e ao adolescente, e que visa resguardar essas pessoas em peculiar condição de desenvolvimento físico, psíquico, moral, espiritual e social, de toda e qualquer forma de punição corporal, envolvendo o castigo físico que provoque sofrimento físico ou lesão, bem como visa coibir tratamento cruel ou degradante que humilhe, ameace gravemente ou ridicularize criança e adolescente. (artigo 18-A e artigo 18B, inseridos no ECA através da Lei n. 13.010/2014).

A Lei da Palmada (Lei n. 13.010/2014), na verdade, traz uma regulação ao art. 227 da Constituição Federal que se limita a mera menção das expressões "tratamento cruel" e "tratamento degradante" e, concomitantemente, tratou de regular e ampliar a redação do art.18 do ECA, especificando as condutas consideradas tratamento cruel ou degradante. Outrossim, almejou enquadrar na ampla expressão "tratamento violento" contida no art. 18 do ECA, o castigo físico como ato de educação, disciplina e correção.

A Lei em comento, tratou de adicionar medidas protetivas e preventivas, não afetando as medidas punitivas já previstas e reguladas pelo ECA, acrescentando à Lei $\mathrm{n}^{\circ}$ 8.069/90 (ECA-Estatuto da Criança e do Adolescente) os artigos 18-A e 18-B que disciplinam a vedação da punição corporal e a aplicação aos pais, professores ou responsável das medidas previstas no art. 129, incisos I, II, III e IV do ECA, buscando o legislador estabelecer o direito da criança e do adolescente de serem educados e cuidados sem o uso de castigos corporais ou de tratamento cruel ou degradante.

É importante frisar que o âmbito de aplicação da Lei da Palmada não se limita à violência doméstica ou intrafamiliar, trata-se de uma Lei cujo âmbito de aplicação de suas disposições envolve os genitores, guardiães, tutores, curadores, terceiros na posse de fato, agentes públicos executores de medidas socioeducativas, bem como a lei é dirigida para qualquer pessoa que tenha criança e adolescente sob sua responsabilidade, ou seja, detentora 
do dever de cuidar, educar, tratar e proteger, portanto, o âmbito de aplicação abrange os professores e educadores em geral.

Inclusive, a Lei da Palmada produziu reflexos na Lei de Diretrizes e Bases da Educação Nacional, conforme já se mencionou alhures, acrescentando ao art. 26 da LDB o parágrafo $9^{\circ}$. que impõe a inserção nos currículos escolares de conteúdos relacionados à educação em Direitos Humanos e às medidas de prevenção contra todas as formas de violências contra a criança e o adolescente. (Lei n. 13.010/2014, art. $3^{\circ}$.)

A Lei da Palmada, em linhas gerais, é uma medida legislativa atrelada ao sistema de proteção à criança e ao adolescente, e que visa resguardá-las de toda e qualquer forma de punição corporal, envolvendo o castigo físico que provoque sofrimento físico ou lesão, bem como tratamento cruel ou degradante que vise humilhar, ameaçar gravemente ou ridicularizar criança e adolescente.

\section{OS REFLEXOS DA LEI DA PALMADA NA LDB: CONTEÚDOS DE DIREITOS HUMANOS E DE PREVENÇÃO DE TODAS A FORMAS DE VIOLÊNCIA CONTRA A CRIANÇA E O ADOLESCENTE}

Conforme esclarecido anteriormente, a Lei da Palmada, além de regulamentar, concomitantemente o art. 227 da CF e o art. 18 do ECA, refletiu diretamente na LDB, ao acrescentar ao artigo 26 da LDB o parágrafo $9^{\circ}$., estabelecendo como dever das escolas a inclusão nos seus currículos escolares, como temas transversais, de conteúdos relativos a direitos humanos e à prevenção de todas as formas de violência contra a criança e o adolescente. Nesse sentido, assim dispõe o art. $3^{\circ}$. da Lei da Palmada:

\footnotetext{
Art. $3^{\Theta}$ O art. 26 da Lei $n^{0}$ 9.394, de 20 de dezembro de 1996 (Lei de Diretrizes e Bases da Educação Nacional), passa a vigorar acrescido do seguinte $\S 9^{\circ}$ : "Art. 26.

$\S 9^{\mathrm{O}}$ Conteúdos relativos aos direitos humanos e à prevenção de todas as formas de violência contra a criança e o adolescente serão incluídos, como temas transversais, nos currículos escolares de que trata o caput deste artigo, tendo como diretriz a Lei $\mathrm{n}^{\mathrm{O}}$ 8.069, de 13 de julho de 1990 (Estatuto da Criança e do Adolescente), observada a produção e distribuição de material didático adequado." (NR)
}

Conteúdos relativos a direitos humanos referem-se, na verdade, à educação em direitos humanos, e, para tanto, há necessidade de se proceder à revisões e planejamentos na 
elaboração dos currículos escolares, além disso, urge investimentos estatais e até mesmo da inciativa privada, na preparação específica dos profissionais da área educacional, visando o envolvimento de todos para a educação em direitos humanos e nas ações e mecanismos de combate e prevenção à todas as formas de violações aos direitos infanto-juvenis.

Portanto, a questão merece, por parte do Estado, tratamento prioritário em matéria de políticas públicas educacionais e de planejamento escolar, pois é através da educação em direitos humanos que se despertará na criança e no adolescente a consciência para uma formação cidadã e humana, onde o homem se torna o centro e fundamento para todas as ações humanas.

A Educação em Direitos Humanos, como tema transversal que deve compor o currículo escolar, merece grande relevância, pois significa muitos mais que transmissão e apreensão de valores éticos e morais como meio de se atingir a formação integral da criança e do adolescente, representa manifestação de ações e atitudes com base no respeito e consideração ao próximo, ações de responsabilidade social e constante prática de solidariedade entre os homens.

Para cumprimento desses objetivos educacionais, elementar o desenvolvimento do projeto pedagógico de forma articulada entre as diversas e multifacetadas áreas do conhecimento, formando, assim, "conteúdos tradicionais que encorpam o eixo longitudinal do sistema educacional e temas identificados com o cotidiano concreto e contínuo dos alunos." (CARNEIRO, 2012, p. 246)

Essa integração e articulação para a formação básica e comum da criança e do adolescente envolve o que se denomina de "temas transversais", que contribuem para a construção de instrumentos de compreensão e intervenção na realidade em que vivem os alunos, cujos temas atribuem ao currículo escolar uma dimensão social, cultural e humana, através de temas éticos-humanistas e, na expressão de Carneiro (2012, p. 247), os temas transversais são como "janelas abertas para o mundo e para a vida", possibilitando a formação integral da pessoa humana, baseada em valores éticos e de respeito ao próximo.

Visando integralizar o sistema de proteção integral e concretizar o sistema de garantias individuais e coletivas à criança e ao adolescente a Lei da Palmada é um mecanismo legislativo que tem o condão de enfrentar a cultura da violência, buscando inserir e promover nos âmbitos da vida individual, escolar, familiar, grupal e social, a cultura dos direitos humanos e de respeito ao próximo, com adoção de medidas de prevenção de violências. 
A Lei n. 13.010 de 26/6/2014, Lei da Palmada, teve como objetivo acrescentar à Lei $\mathrm{n}^{\mathrm{o}}$ 8.069, de 13 de julho de 1990 (Estatuto da Criança e do Adolescente) o direito da criança e do adolescente de serem educados e cuidados sem o uso de castigos físicos ou de tratamento cruel ou degradante, inserido no ECA os artigos 18A e 18B, além disso, a Lei da Palmada refletiu diretamente na LDB e acrescentou ao artigo 26 da Lei $n^{0}$ 9.394, de 20 de dezembro de 1996 (Lei de Diretrizes e Bases da Educação Nacional) o parágrafo 9º que prevê a inclusão nos currículos escolares, como temas transversais, de conteúdos relativos a direitos humanos e à prevenção de todas as formas de violência contra a criança e o adolescente.

Dessa forma, considerando os reflexos da Lei da Palmada, o art. 26 da LDB passou a compor a seguinte redação:

Art. 26. Os currículos da educação infantil, do ensino fundamental e do ensino médio devem ter base nacional comum, a ser complementada, em cada sistema de ensino e em cada estabelecimento escolar, por uma parte diversificada, exigida pelas características regionais e locais da sociedade, da cultura, da economia e dos educandos. (Redação dada pela Lei $n^{\circ} 12.796$, de 2013)

$\S 1^{\circ}$ Os currículos a que se refere o caput devem abranger, obrigatoriamente, o estudo da língua portuguesa e da matemática, o conhecimento do mundo físico e natural e da realidade social e política, especialmente do Brasil.

$\S 2^{\mathrm{O}} \quad \mathrm{O}$ ensino da arte, especialmente em suas expressões regionais, constituirá componente curricular obrigatório nos diversos níveis da educação básica, de forma a promover o desenvolvimento cultural dos alunos. (Redação dada pela Lei $\mathrm{n}^{\circ} 12.287$, de 2010)

§ 3o A educação física, integrada à proposta pedagógica da escola, é componente curricular obrigatório da educação básica, sendo sua prática facultativa ao aluno: (Redação dada pela Lei $\mathrm{n}^{\mathbf{o}} 10.793$, de $1^{\circ} .12 .2003$ )

I - que cumpra jornada de trabalho igual ou superior a seis horas; (Incluído pela Lei $\mathrm{n}^{\circ}$ 10.793, de $1^{\circ} .12 .2003$ )

II - maior de trinta anos de idade; (Incluído pela Lei ${ }^{\circ} 10.793$, de $1^{\circ} .12 .2003$ )

III - que estiver prestando serviço militar inicial ou que, em situação similar, estiver obrigado à prática da educação física; (Incluído pela Lei $\mathrm{n}^{\circ} 10.793$, de $1^{\circ} .12 .2003$ )

IV - amparado pelo Decreto-Lei no 1.044, de 21 de outubro de 1969; (Incluído pela Lei $\mathrm{n}^{\mathrm{o}} 10.793$, de $\left.1^{\circ} .12 .2003\right)$

$\mathrm{V}-\left(\right.$ VETADO) (Incluído pela Lei $\mathrm{n}^{\mathrm{o}} 10.793$, de $1^{\mathrm{o}}$.12.2003)

$\mathrm{VI}$ - que tenha prole. (Incluído pela Lei $\mathrm{n}^{\mathrm{o}} 10.793$, de $1^{\circ} .12 .2003$ )

$\S 4^{\circ} \mathrm{O}$ ensino da História do Brasil levará em conta as contribuições das diferentes culturas e etnias para a formação do povo brasileiro, especialmente das matrizes indígena, africana e européia.

$\S 5^{\circ} \mathrm{Na}$ parte diversificada do currículo será incluído, obrigatoriamente, a partir da quinta série, o ensino de pelo menos uma língua estrangeira moderna, cuja escolha ficará a cargo da comunidade escolar, dentro das possibilidades da instituição.

§ 6o A música deverá ser conteúdo obrigatório, mas não exclusivo, do componente curricular de que trata o $§ 20$ deste artigo. (Incluído pela Lei $n^{\circ} 11.769$, de 2008)

$\S 7$ o Os currículos do ensino fundamental e médio devem incluir os princípios da proteção e defesa civil e a educação ambiental de forma integrada aos conteúdos obrigatórios. (Incluído pela Lei no 12.608, de 2012)

$\S 8^{\circ}$ A exibição de filmes de produção nacional constituirá componente curricular complementar integrado à proposta pedagógica da escola, sendo a sua exibição obrigatória por, no mínimo, 2 (duas) horas mensais. (Incluído pela Lei $\mathrm{n}^{\circ}$ 13.006, de 2014)

§ 9o Conteúdos relativos aos direitos humanos e à prevenção de todas as formas de violência contra a criança e o adolescente serão incluídos, como temas transversais, nos 
currículos escolares de que trata o caput deste artigo, tendo como diretriz a Lei no 8.069, de 13 de julho de 1990 (Estatuto da Criança e do Adolescente), observada a produção e distribuição de material didático adequado. (Incluído pela Lei $\mathrm{n}^{\circ} 13.010$, de 2014) (Disponível em :http://www.planalto.gov.br/ccivil_03/Leis/L9394.htm, acesso em 10 de julho de 2015)

A vulnerabilidade da criança e do adolescente os tornam vítimas em potencial de atos de violência nos vários cenários onde vivem e convivem, notadamente no âmbito doméstico, escolar, espaços recreativos etc, cujas violências se manifestam de variadas formas: física, psíquica, sexual, negligência etc.

Denota-se que a proposta legislativa é efetivar a formação integral da criança e do adolescente através da conscientização, proteção e promoção dos direitos humanos, universalmente consagrados através da Declaração Universal dos Direitos Humanos (ONU, 1948), agregando ao sistema de proteção e promoção aos direitos humanos a prevenção de toda e qualquer forma de violência atentatória à dignidade da pessoa humana em relação à criança e ao adolescente, pois somente se concretizará a educação em direitos humanos com a educação para a prevenção da violência, ou seja, através da adoção de um sistema educativo preventivo.

A LDB já vem caminhando gradativamente para a transversalidade, inclusive, em seu art. 32, parágrafo $5^{\circ}$., prevê a transversalidade e formação básica e cidadã da criança e do adolescente, determinando que "o currículo do Ensino Fundamental incluirá, obrigatoriamente, conteúdo que trate dos direitos da criança e dos adolescentes, tendo como diretriz a Lei n. 8.069, de 13/7/90, que institui o Estatuto da Criança e do Adolescente, observada a distribuição de material didático adequado."

No mesmo sentido, o art. 26 da LDB, conforme se verifica acima, passou por constantes alterações e inclusões de novas disposições, todas voltadas para a transversalidade e formação completa e integral do educando.

Depreende-se, assim, que a cultura da paz na escola, o desenvolvimento da consciência cidadã e a capacidade de compreensão e apreensão dos Direitos Humanos, exige a inserção nos currículos da cultura e valores em Direitos Humanos, mas, a apreensão e ações práticas voltadas para os direitos humanos requer também a inserção do tema transversal referido na Lei da Palmada e relacionado à prevenção da violência contra a criança e o adolescente, como conteúdo e forma complementar à Educação em Direitos Humanos, visando, dessa forma, concretizar o disposto no Preâmbulo da Convenção sobre os Direitos da Criança (ONU, 1989), ou seja, a criança deve ser educada num espírito de paz, harmonia, respeito, tolerância, dignidade e solidariedade. 


\section{CONCLUSÃO}

A educação, sem dúvida, é um mecanismo eficiente de inclusão e formação para a cidadania, e, assim sendo, reduz as consequências da desigualdade social, diante da igualdade de oportunidades, sendo, portanto, essencial para concretização do princípio da igualdade entre os homens.

Contudo, a educação somente será capaz de transformar pessoas conscientes, de espírito e ação cidadã, com atitudes humanas e de respeito e consideração ao próximo e à diversidade ambiental, bem como a escola deixará de ser um local de depósito de saberes e experiências com exigência de reprodução desses saberes, para se tornar um espaço de socialização e formação plena e integral, quando se ensina e adota ações voltadas para o respeito aos direitos humanos e respeito à biodiversidade.

Nesse sentido, urge, de fato, uma cautela com a formação dos conteúdos que comporão os currículos escolares, justamente para agregar teorias e práticas envolvendo ensinamentos e experiências voltadas para os Direitos Humanos e prevenção de todas as formas de violência que atentem à dignidade da pessoa humana, especialmente, das crianças e adolescentes, que são sujeitos de direitos em peculiar condição de desenvolvimento físico, psíquico, moral, educacional, social e espiritual.

Os conteúdos curriculares passam por constantes revisões a fim de atender às necessidades educativas e de formação das crianças, adolescentes e jovens nos tempos modernos, o que provoca constantes revisões e alterações na LDB, inclusive, por força de outras Leis, tal como ocorreu com a Lei da Palmada (Lei n. 13010/2014) que alterou a LDB buscando ampliar o conteúdo curricular para possibilitar a formação humana e com responsabilidade social da criança e do adolescente. 


\section{REFERÊNCIAS}

ALKIMIN, Maria Aparecida (org.) Bullying: visão interdisciplinar. Campinas, SP: Editora Alínea, 2011.

ALMEIDA, Guilherme Assis de; SELMI, Silvia Menicucci de Oliveira. Direitos Humanos. Série Leituras Jurídicas: provas e concursos. v. 34. São Paulo: Atlas, 2009.

BERLINI, Luciana Fernandes. Lei da Palmada: uma análise sobre a violência doméstica infantil. Belo Horizonte: Arraes Editores, 2014.

BOBBIO, Norberto. A Era dos Direitos. Trad. Carlos Nelson Coutinho. Apresentação de Celso Lafer. Rio de Janeiro: Elsevier, 2004.

BRASIL. Lei 8.069, de 13.07.1990. Dispõe sobre o Estatuto da Criança e do Adolescente, 13.07.1990. Disponível em: www.planalto.gov.br/ccivil_03/leis/18069.html. Acesso em: 30 jul 2015

BRASIL. Lei 13.010, de 26 de junho de 2014. Altera a Lei no 8.069, de 13 de julho de 1990 (Estatuto da Criança e do Adolescente), para estabelecer o direito da criança e do adolescente de serem educados e cuidados sem o uso de castigos físicos ou de tratamento cruel ou degradante, e altera a Lei no 9.394, de 20 de dezembro de 1996. Disponível em: http://www.planalto.gov.br/ccivil_03/_Ato2011-2014/2014/Lei/L13010.htm. Acesso em: 30 jul 2015.

BRASIL. Constituição da República Federativa do Brasil. Brasília: Senado Federal, 1988. Disponível em: www.planalto.gov.br/ccivil_03/constituicao/constituicao.htm. Acesso em: 30 jul 2015.

BRASIL, Lei n. 9.394 de 20 de dezembro de 1996- Lei de Diretrizes e Bases da Educação Nacional. 9.ed. Disponível em: http://www.sinprosp.org.br/arquivos/direitos/ldb_artigos_26_36.pdf. Acesso em: 08 ago 2015.

BRASIL. Parâmetros curriculares nacionais : introdução aos parâmetros curriculares nacionais / Secretaria de Educação Fundamental. - Brasília : MEC/SEF, 1997. Disponível em: http://portal.mec.gov.br/seb/arquivos/pdf/livro01.pdf. Acesso em: 08 ago 2015

BRASIL. Plano Nacional de Educação em Direitos Humanos - Comitê Nacional de Educação em Direitos Humanos, da Secretaria Especial dos Direitos Humanos/Presidência da República, Ministério da Educação; Ministério da Justiça-Brasília.UNESCO, 2007. Disponível em: portal.mec.gov.br/index.php?option=com_docman\&task...Acesso em: 08 ago 2015 .

CANDAU, Vera Maria (Org.). Reinventar a Escola. Petrópolis, RJ: Vozes.

CARNEIRO, Moaci Alves. LDB fácil: leitura crítico-compreensiva, artigo a artigo. 20. ed. atual. e ampl. Petrópolis: RJ, 2012. 
COMPARATO, Fábio Konder. A afirmação histórica dos Direitos Humanos. 3. ed. rev. e ampl. São Paulo: Saraiva, 2003.

CONVENÇÃO INTERNACIONAL DOS DIREITOS DA CRIANÇA. Disponível em: Www.planalto.gov.br/ccivil_03/decreto/1990-1994/D99710.htm. Acesso em: 30 jul 2015.

DECLARAÇÃO DOS DIREITOS DAS CRIANÇAS. Disponível em: www.direitoshumanos.usp.br/index.php/Crian\%C3\%A7a/declaracao-dos-direitos-dacrianca.html. Acesso em: 30 jul 2015.

FORACCHI, Marialice; PEREIRA, Luiz. Educação e Sociedade: Leituras de sociologia da educação. $6^{\text {a }}$. edição. São Paulo: Companhia Editora Nacional, 1971.

SILVA, Aida Maria Monteiro; TAVARES, Celma (Orgs.). Políticas e fundamentos da educação em direitos humanos. São Paulo: Cortez, 2010.

PEREIRA, Tânia da Silva. Direito da Criança e do Adolescente-Uma proposta interdisciplinar. $2^{\mathrm{a}}$.ed. rev. e atual. Rio de Janeiro: Renovar, 2008.

TEIXEIRA, Anísio Teixeira. Educação é um direito. Rio de Janeiro: UFRJ, 1996.

TELLES JUNIOR, Goffredo. Iniciação à Ciência do Direito. $4^{\text {a }}$.ed. rev. e atual. São Paulo: Saraiva, 2008. 